\title{
Anticipating the Unpredictable: A Review of Antimicrobial Stewardship and Acinetobacter Infections
}

\author{
Eric Wenzler · Debra A. Goff · Romney Humphries · Ellie J. C. Goldstein
}

Received: January 27, 2017 / Published online: March 4, 2017

(C) The Author(s) 2017. This article is published with open access at Springerlink.com

\begin{abstract}
Acinetobacter remains one of the most challenging pathogens in the field of infectious diseases owing primarily to the uniqueness and multiplicity of its resistance mechanisms. This resistance often leads to devastatingly long delays in time to appropriate therapy and increased mortality for patients afflicted with Acinetobacter infections. Selecting appropriate empiric and definitive antibacterial therapy for
\end{abstract}

Enhanced content To view enhanced content for this article go to http://www.medengine.com/Redeem/ 62F7F060122AE447.

\section{E. Wenzler $(\bowtie)$}

College of Pharmacy, University of Illinois at

Chicago, Chicago, IL, USA

e-mail: wenzler@uic.edu

\section{A. Goff}

Department of Pharmacy, The Ohio State University

Wexner Medical Center, Columbus, OH, USA

R. Humphries

Department of Pathology and Laboratory Medicine, David Geffen School of Medicine, University of

California, Los Angeles, USA

\section{E. J. C. Goldstein}

Department of Medicine, David Geffen School of

Medicine, University of California, Los Angeles, CA, USA

E. J. C. Goldstein

R M Alden Research Laboratory, Santa Monica, CA, USA
Acinetobacter is further complicated by the lack of reliability in commercial antimicrobial susceptibility testing devices and limited breakpoint interpretations for available agents. Existing treatment options for infections due to Acinetobacter are limited by a lack of robust efficacy and safety data along with concerns regarding appropriate dosing, pharmacokinetic/ pharmacodynamic targets, and toxicity. Antimicrobial stewardship programs are essential to combat this unpredictable pathogen through use of infection prevention, rapid diagnostics, antibiogram-optimized treatment regimens, and avoidance of overuse of antimicrobials. The drug development pipeline includes several agents with encouraging in vitro activity against Acinetobacter, but their place in therapy and contribution to the armamentarium against this pathogen remain to be defined. The objective of this review is to highlight the unique challenge of treating infections due to Acinetobacter and summarize recent literature regarding optimal antimicrobial treatment for this pathogen. The drug development pipeline is also explored for future potentially effective treatment options.

Keywords: Antimicrobial stewardship; Acinetobacter; Combination therapy; Outcomes; Pipeline; Resistance; Susceptibility; Synergy; Treatment 


\section{INTRODUCTION}

Infections due to antibiotic-resistant bacteria are responsible for significant morbidity, mortality, and excess healthcare costs [1]. Of these resistant organisms, Acinetobacter remains one of the most formidable opponents, as its unique and eclectic resistance mechanisms allow it to escape the activity of the majority of our currently available antimicrobials. This pathogen is a member of the ESKAPE [Enterococcus faecium, Staphylococcus aureus, Klebsiella pneumoniae, Acinetobacter baumannii (AB), Pseudomonas aeruginosa, and Enterobacter spp.] group which have been highlighted for their resistance and association with negative clinical outcomes [2]. The mortality rate due to multidrug-resistant (MDR; i.e. non-susceptibility to at least one agent in three or more antimicrobial categories) [3] healthcare-associated $\mathrm{AB}$ alone is approximately $10.6 \%$, with an estimated cost per infection ranging from US\$33,510 to $\$ 129,917$ [4]. So-called "superbugs" like MDR Acinetobacter undermine decades of advances made in medicine, surgery, and transplantation. The acquisition of resistance mechanisms is increasing in frequency among this pathogen [5], leading to extensively (XDR; i.e. non-susceptibility to at least one agent in all but two or fewer antimicrobial categories) [3] resistant isolates and threatening the effectiveness of our remaining antibiotics, including those used as last-resort therapeutic options. This resistance poses significant challenges when selecting empiric antibiotic therapy and often leads to devastatingly long delays in time to appropriate therapy. While these delays undoubtedly lead to increases in mortality $[6,7]$, knowledge of local susceptibilities and application of antimicrobial stewardship practices can work to improve outcomes.

Few currently available and pipeline agents have reliable activity against Acinetobacter. As a result, clinicians are forced to resort to older agents with more narrow therapeutic windows and a paucity of modern efficacy data to support their use, including the polymyxins, tetracyclines, and the aminoglycosides. This review will discuss the challenge of treating infections due to Acinetobacter and summarize recent literature regarding optimal antimicrobial treatment. We will also explore the horizon for antimicrobials in the development pipeline with activity against this pathogen. This article is based on previously conducted studies and does not involve any new studies of human or animal subjects performed by any of the authors.

\section{MICROBIOLOGY AND PATHOGENICITY}

Bacteria within the genus Acinetobacter are ubiquitous, encapsulated, non-lactose fermentative, oxidase-negative Gram-negative coccobacilli. The vast majority of infections are caused by the Acinetobacter calcoaceticus-baumannii complex, which is comprised of $A$. calcoaceticus, A. baumannii, A. nosocomialis, and $A$. pittii, with $A$. baumannnii (AB) being the most clinically important species responsible for the highest incidence of MDR and mortality compared to other Acinetobacter species [8]. AB may survive on wet or dry inanimate surfaces for up to 4 months [9], and can colonize patients for up to 42 months, which may contribute to its endemicity and proclivity for outbreaks [10]. Acquisition and spread of $\mathrm{AB}$ has been noted particularly in long-term care and skilled nursing facilities.

The exact reason for the success of the Acinetobacter spp. is largely unknown. Although its name is loosely derived from the Greek word akineto, meaning "non-motile", $\mathrm{AB}$ actually possesses several core motility genes which can assemble pilli and produce motility under certain conditions, and may contribute to its ability to spread on fomites and form biofilms [11]. $\mathrm{AB}$ specifically possesses several features that may enhance its survival, including simple growth requirements and resistance to the natural bactericidal activity of human complement [12]. Acinetobacter has the ability to acquire and rearrange genetic material, leading to new and enhanced virulence and antimicrobial resistance. Its virulence mechanisms are not well understood, but include its outer membrane porins, surface capsules and lipopolysaccharide, 
iron acquisition systems, and regulatory proteins. The implication of these mechanisms in disease transmission and pathogenicity have been reviewed in detail elsewhere [8].

$A B$ primarily causes nosocomial infections, although community-acquired infections have been reported [13] and are increasing nationally and internationally [14-16]. Globally, the incidence of MDR AB exceeds $75 \%$ in Africa, Asia, and Latin America and 90\% in parts of Europe and the Middle East [17]. In the U.S., carbapenem-resistant $\mathrm{AB}$ (CRAB) increased from $9 \%$ in 1995 to $40 \%$ in 2004 [18]. A 2011 survey of 11 Latin American countries found that more than $50 \%$ of $\mathrm{AB}$ were carbapenem-resistant [19] compared to rates as high as $85 \%$ in Turkey, Greece, Italy, Spain, and England [20]. Pneumonia is the most common $\mathrm{AB}$ infection, and the majority (57.6\%) of $\mathrm{AB}$ isolates in the U.S. are cultured from the respiratory tract, followed by the bloodstream (23.9\%), and skin and soft tissue $(9.1 \%)$ [21]. AB is the fifth leading cause of ventilator-associated pneumonia (VAP) and 13th of central line-associated bloodstream infections [22]. Risk factors for $\mathrm{AB}$ infection include prolonged hospital/ICU stay, immunosuppression, invasive devices and procedures, mechanical ventilation, and broad-spectrum antibiotic exposure [18]. AB infections tend to occur in vulnerable, debilitated patients including those in ICUs and residents of longterm care facilities, especially those who are ventilator-dependent. The mortality rate for these serious infections due to $\mathrm{AB}$ varies by geography and type of infection, but is roughly $30-75 \%$.

\section{MECHANISMS OF RESISTANCE}

In the 1970s, $A B$ was routinely susceptible to ampicillin and cephalosporins. By the 1990s, resistance to carbapenems had emerged and current reports describe strains resistant to all available antimicrobials, including colistin, polymyxin $\mathrm{B}$, and tigecycline [23]. This in vitro resistance has been associated with negative clinical outcomes including increased ICU length of stay and mortality [8]. Table 1 provides a summary of commonly identified mechanisms of resistance in $\mathrm{AB}$. Compared to other Gram-negative pathogens, the ability to and ease with which $\mathrm{AB}$ acquires new resistance mechanisms via plasmids, transposons, and integrons is quite remarkable. $\mathrm{AB}$ employs a myriad of resistance mechanisms, including enzymatic hydrolysis, target site alterations, porin loss, and efflux pumps. In contrast to many other Gram-negative species, these mechanisms are often employed in combination in MDR AB isolates [24].

Ambler class A extended spectrum $\beta$-lactamase (ESBL) enzymes are becoming increasingly common in non-fermenting Gram-negative pathogens like $\mathrm{AB}$. The most common are the PER-, VEB- and GES-types [24]. These enzymes have been identified throughout the world, with PER-1 being the most common in the U.S. The next most common ESBL in $\mathrm{AB}$, the Vietnamese ESBL (VEB), shares only $38 \%$ amino acid identity with PER-1, speaking to the diversity and challenging nature of $\mathrm{AB}$ resistance mechanisms [25]. Additionally, GES-type ESBLs, which possess amplified hydrolytic activity towards aztreonam and ceftazidime, have been increasingly reported in $\mathrm{AB}$ since 2010 [26]. Conversely, common ESBL enzymes found in Enterobacteriaeceae, like TEM-, SHV-, and CTX-M-types, have rarely been identified in $\mathrm{AB}$ and may be due to limited horizontal gene transfer as a result of narrow-spectrum plasmid replication properties [24]. Unlike Enterobacteriaceae spp., KPC enzymes have rarely been identified in $\mathrm{AB}$ and are not a major player in its resistance armamentarium.

Class B metallo- $\beta$-lactamase enzymes have also been identified in $\mathrm{AB}$ with increasing frequency, including IMP-, VIM-, SIM-, and NDM-type enzymes. These zinc-based enzymes confer resistance to $\beta$-lactams and carbapenems, and are not inhibited by clinically available $\beta$-lactamase inhibitors [27]. At least 9 different IMP varieties have been identified in $A B$ around the world [28-32], while the Seoul imipenemase (SIM-1) carbapenemase has to date been reported only in South Korea and China [33, 34]. NDM-1 and NDM-2 have also been reported in $\mathrm{AB}$, primarily in China, Europe, Africa, and the Middle East [35].

One of AB's primary mechanisms of resistance to commonly utilized first-line 
Table 1 Common mechanisms of resistance in Acinetobacter baumannii

\begin{tabular}{|c|c|c|}
\hline Mechanism & Type & Conferred resistance \\
\hline PER & $\begin{array}{l}\text { Acquired extended-spectrum } \\
\beta \text {-lactamase }\end{array}$ & Penicillins, cephalosporins, monobactams \\
\hline VEB & $\begin{array}{l}\text { Acquired extended-spectrum } \\
\beta \text {-lactamase }\end{array}$ & Penicillins, cephalosporins, monobactams \\
\hline GES & $\begin{array}{l}\text { Acquired extended-spectrum } \\
\beta \text {-lactamase }\end{array}$ & Penicillins, cephalosporins, monobactams \\
\hline TEM & Acquired serine $\beta$-lactamase & Penicillins, cephalosporins, monobactams, sulbactam \\
\hline IMP & Acquired metallo- $\beta$-lactamase & Penicillins, cephalosporins, carbapenems, $\beta$-lactamase inhibitors \\
\hline SIM & Acquired metallo- $\beta$-lactamase & Penicillins, cephalosporins, carbapenems, $\beta$-lactamase inhibitors \\
\hline NDM & Acquired metallo- $\beta$-lactamase & Penicillins, cephalosporins, carbapenems, $\beta$-lactamase inhibitors \\
\hline $\mathrm{ADC}$ & Intrinsic AmpC $\beta$-lactamase & $\begin{array}{l}\text { Aminopenicillins, oxyiminocephalosporins, cephamycins, } \\
\beta \text {-lactamase inhibitors }\end{array}$ \\
\hline$-\mathrm{ADC}-33$ & Intrinsic AmpC $\beta$-lactamase & $\begin{array}{l}\text { Aminopenicillins, oxyiminocephalosporins, cephamycins, cefepime, } \\
\beta \text {-lactamase inhibitors }\end{array}$ \\
\hline$-\mathrm{ADC}-56$ & Intrinsic AmpC $\beta$-lactamase & $\begin{array}{l}\text { Aminopenicillins, oxyiminocephalosporins, cephamycins, cefepime, } \\
\beta \text {-lactamase inhibitors }\end{array}$ \\
\hline OXA & Intrinsic serine carbapenemase & Oxacillin, clavulanate, sulbactam, tazobactam \\
\hline AdeABC & $\begin{array}{l}\text { Resistance-nodulation-cell division } \\
\text { efflux pump }\end{array}$ & Aminoglycosides, fluoroquinolones, tetracyclines, trimethoprim \\
\hline Tet & Efflux pump & Tetracyclines, tigecycline \\
\hline PmrAB & $\begin{array}{l}\text { Two-component regulatory system } \\
\text { alterations }\end{array}$ & Polymyxins \\
\hline $\begin{array}{l}\text { LpxA, LpxC, } \\
\text { LpxD }\end{array}$ & Loss of LPS production & Polymyxins \\
\hline ArmA & 16S RNA methyltransferase & Aminoglycosides \\
\hline GyrA & DNA gyrase alterations & Fluoroquinolones \\
\hline ParC & DNA topoisomerase IV alterations & Fluoroquinolones \\
\hline RpoB & RNA polymerase alterations & Rifampin \\
\hline
\end{tabular}

antimicrobials are Class $C \beta$-lactamases. A wide variety of AmpC-type cephalosporinases have been identified in $\mathrm{AB}$ and subsequently named Acinetobacter-derived cephalosporinase (ADC) enzymes. Importantly, some of these ADC variants such as ADC-33 and ADC-56 have extended spectrums which allow them to hydrolyze cefepime, whereas wild-type AmpC such as those often found in Enterobacteriaceae do not $[36,37]$.

Class D $\beta$-lactamase production, primarily of the OXA-type, exhibit low-level carbapenemase activity and are only weakly expressed in most $\mathrm{AB}$ isolates. Overexpression can occur and lead 
to carbapenem nonsusceptibility when combined with other mechanisms. The OXA-23 enzyme is the most widespread and has been identified on all inhabited continents [27].

$\mathrm{AB}$ has also demonstrated the ability to confer resistance to aminoglycosides, fluoroquinolones, tetracyclines, and trimethoprim through complex efflux systems such as the resistance-nodulation-cell division system [38, 39]. Tigecycline maintains in vitro activity against $A B$, and the mechanisms of resistance in cases of resistant isolates is likely due to efflux pumps. Resistance to colistin has been described and is commonly due to either alterations of the lipid A component of the lipopolysaccharide (LPS) [40] or complete loss of LPS production [41], although diversity among polymyxin resistance mechanisms is beginning to be described [42].

Worldwide, less than $30 \%$ of $\mathrm{AB}$ are fluoroquinolone-susceptible [17], due to mutations in the quinolone resistance determining regions of gyrA and parC genes and/or overexpression of efflux pumps [12]. Resistance to aminoglycosides exceeds $60 \%$ in most countries and is due primarily to production of aminoglycoside-modifying enzymes like ArmA, or efflux pumps. The major mechanism underlying rifampin resistance is substitution of amino acids in the target protein, commonly occurring through a single mutation to the $r p o B$ gene.

\section{ANTIMICROBIAL SUSCEPTIBILITY TESTING}

Laboratories in the U.S. have reached a critical juncture in their ability to perform antimicrobial susceptibility testing (AST) as a result of regulatory changes that limit test menus of commercial AST devices (cASTs). These changes drastically limit the ability to test Acinetobacter spp., a genus for which antibiotic susceptibility is rarely predictable. As such, timely and accurate AST of Acinetobacter isolates is critical to the management of patients. In the U.S., two organizations establish breakpoints-the Clinical and Laboratory Standards Institute (CLSI) and the U.S. Food and Drug Administration (FDA). The vast majority of U.S. laboratories perform susceptibility testing using cASTs, which are regulated by the FDA; by U.S. law, cASTs must use FDA breakpoints. This presents a major challenge for Acinetobacter spp., as FDA only grants breakpoints for those organisms against which a given antibiotic has proven activity, both in vitro and in clinical infections (i.e., organisms listed in the drug monograph under clinical indications for use) [43]. Only 9 antibiotics have an FDA-approved clinical indication for use for Acinetobacter spp. (Table 2). Given the complexity of clinical trial design and relative infrequency of infections caused by Acinetobacter spp., it is unlikely that new antimicrobials will achieve indications for treatment of Acinetobacter. As of November 2017, Language in the 21st Century Cures Act allows the FDA to designate breakpoints set by standard setting organizations, like CLSI, for use with cASTS. CLSI can establish breakpoints independent of a pharmaceutical sponsor, as occurred for colistin in 2015 [44]. However, even if CLSI Acinetobacter breakpoints are recognized by the FDA, it may be years before a test is cleared for those antibiotics on the automated cASTs that are used by most laboratories (e.g., Vitek 2, Microscan) [43], as development and marketing of new cASTS typically takes 3-7 years. There is a lack of prioritization for development of such cASTs by the manufacturers [43].

It should be noted that tests are available for Acinetobacter spp. outside the U.S, in countries where manufacturers of cASTs are not subject to FDA oversight. Furthermore, many laboratories are able to perform susceptibility testing of Acinetobacter spp. using CLSI breakpoints for some drugs using FDA-cleared cASTs (Table 2). This is because these devices were cleared prior to 2007, the year FDA started enforcing regulations requiring use of FDA breakpoints on cASTs. However, the ability of these systems to detect resistance mechanisms that have emerged or become more common since 2007 is unknown [43]. To further complicate matters, several differences exist between CLSI and FDA Acinetobacter breakpoints for the carbapenems (Table 2). CLSI updated Acinetobacter carbapenems breakpoints in 2012, in light of updated PK/ PD and clinical outcome data, but FDA has yet to make adjustments. This is a critical issue, as CLSI updates to breakpoints are designed to 
Table 2 CLSI and FDA breakpoints for Acinetobacter spp

\begin{tabular}{|c|c|c|c|}
\hline \multirow[t]{2}{*}{ Antibiotic } & \multicolumn{2}{|c|}{ Susceptible breakpoints $(\mu \mathrm{g} / \mathrm{mL})$} & \multirow[t]{2}{*}{ FDA cleared cAST } \\
\hline & $\overline{\text { CLSI }}$ & FDA & \\
\hline Ampicillin-sulbactam & $\leq 8 / 4$ & $\leq 8^{\mathrm{a}}$ & All automated systems, Etest and disk \\
\hline Piperacillin-tazobactam & $\leq 16 / 4$ & $\leq 16 / 4^{\mathrm{b}}$ & All automated systems, Etest and disk \\
\hline Ceftazidime & $\leq 8$ & None & \\
\hline Cefepime & $\leq 8$ & None & \\
\hline Cefotaxime & $\leq 8$ & $\leq 8$ & \\
\hline Ceftriaxone & $\leq 8$ & None & \\
\hline Doripenem & $\leq 2$ & $\leq 1$ & \\
\hline Imipenem & $\leq 2$ & $\leq 4$ & All automated systems, Etest and disk \\
\hline Meropenem & $\leq 2$ & None & \\
\hline Polymyxin B & $\leq 2$ & None & None \\
\hline Colistin & $\leq 2$ & None & None \\
\hline Gentamicin & $\leq 4$ & None & \\
\hline Tobramycin & $\leq 4$ & None & \\
\hline Amikacin & $\leq 16$ & $\leq 16$ & \\
\hline Doxycycline & $\leq 4$ & $\leq 4$ & \\
\hline Minocycline & $\leq 4$ & $\leq 4$ & Etest and disk \\
\hline Tetracycline & $\leq 4$ & $\leq 4$ & \\
\hline Ciprofloxacin & $\leq 1$ & None & \\
\hline Levofloxacin & $\leq 2$ & None & \\
\hline Trimethoprim-sulfamethoxazole & $\leq 2 / 38$ & None & \\
\hline Tigecycline $^{c}$ & None & None & None \\
\hline
\end{tabular}

${ }^{a}$ For Acinetobacter calcoaceticus only

${ }^{\mathrm{b}}$ For $A$. baumannii only

${ }^{c}$ Many use a functional breakpoint of $\leq 2 \mathrm{ug} / \mathrm{mL}$, but this has not been clinically validated

detect clinically relevant resistance that might be missed by historical (FDA) breakpoints.

\section{PRACTICAL APPROACHES TO AST OF ACINETOBACTER SPP.}

The performance of available cASTs for detecting resistance in Acinetobacter spp. is unknown as almost no studies performed in the past 10 years utilized current breakpoints and contemporary isolates. Only one recent, systematic evaluation of Vitek 2 as compared to CLSI reference MICs has been performed, including a small sample of 26 isolates of $A$. baumannii. In this study, only 1 very major error (i.e., false susceptibility) was noted, for tobramycin, among 364 overall readings. In 
contrast, between $11.5 \%$ and $30.7 \%$ minor errors (i.e., intermediate MIC by Vitek2 and susceptible by the reference method) were noted for the $\beta$-lactam/ $\beta$-lactamase inhibitor combinations and cephems. This high incidence of minor errors could potentially reduce use of these drugs for treatment of $A B$, as many clinicians view the intermediate and resistant interpretations to be synonymous [45]. Two additional studies evaluated the performance of various methods for testing activity of tetracyclines against CRAB [46, 47]. From these studies, it is apparent that Etest (bioMerieux, Durham, NC, USA) yields elevated MICs for minocycline, tigecycline and doxycycline, again resulting in rates of false non-susceptibility ranging from 15 to $37 \%$. This observation varied by manufacturer of the Mueller-Hinton agar used, highlighting the critical importance of cation content in testing media for the tetracyclines, and in particular tigecycline [46]. In contrast, broth-based MIC methods, including Vitek 2 and Sensititre panels, performed well.

One option for testing antibiotics is off-line testing using manual, research-use-only (RUO) MIC tests (such as Sensititre panels made by ThermoFisher, or in some cases Etest). This approach allows interpretation of MICs by CLSI breakpoints, or reporting of MICs without interpretation if no breakpoint exists (for example, for tigecycline). Laboratories that take the RUO MIC approach should perform a verification study to ensure the RUO test yields results that are accurate as compared to CLSI reference broth microdilution method, and include a disclaimer on patient reports indicating testing was performed using a device that is not cleared by the FDA [43]. Performing a verification study for RUO products is critical, as not all RUO tests perform acceptably for detecting resistance, and may not yield reproducible results. For example, RUO colistin disk and Etest have been shown in several studies to yield unacceptably high rates of false susceptibility and false resistance, when compared to CLSI broth microdilution [48], the only method endorsed by CLSI and EUCAST for testing the polymyxins [49].

\section{ANTIBIOGRAM DATA}

Cumulative institution-level antibiogram data can be of significant value when evaluating empiric treatment options prior to receipt of antimicrobial susceptibility data. However, the integrity of data used to generate the antibiogram is crucial. The vast majority of laboratories produce antibiograms from data generated by cAST, which may be associated with bias towards overcalling resistance. Additionally, the number of isolates tested per antibiotic is important. If a laboratory performs off-line testing for a given agent (for example, minocycline or colistin), it is likely that only more resistant isolates would be tested against these drugs. For example, the data presented in Table 3 from one of our laboratories documents $54.4 \%$ of $\mathrm{AB}$ isolates were susceptible to meropenem in 2015 ( $n=119$ patients tested). In this same year, only $4.3 \%$ of isolates were susceptible to doripenem ( $n=65$ patients tested), because doripenem was tested using an off-line panel and only for isolates that were not susceptible to one or more carbapenems. This being said, knowledge of cumulative susceptibility for more resistant isolates alone may be of use-for example, when waiting for the laboratory to perform off-line testing for agents like minocycline, tigecycline or colistin for the patient with a carbapenem-resistant A. baumannii infection (Table 3).

Generally speaking, if $<30$ isolates were tested in a given year, that species should not be included in the cumulative antibiogram as it makes the data less generalizable to future isolates. For instance, in Table 3, we have calculated the antibiogram for all isolates of $A$. baumannii recovered from all hospital inpatients in our institution $(n=119$ patients/isolates) versus only those recovered from patients in the ICU ( $n=21$ patients/isolates). While the percent of isolates susceptible to colistin is very similar $(93.6 \%$ and $90.0 \%$, respectively), the 95\% confidence interval surrounding these data is very broad-at the low end $74.9 \%$ versus $45.9 \%$ susceptible. While these data may still be useful, it is important to report the number of isolates included in antibiogram calculations. 
Table 3 Demonstration of the impact of number of isolates on confidence for data and effect of inclusion of duplicate isolates in the antibiogram

\begin{tabular}{|c|c|c|c|c|c|}
\hline \multirow[b]{2}{*}{ Antibiotic } & \multicolumn{2}{|c|}{$\begin{array}{l}\text { All isolates, all } \\
\text { patients }(n=125)\end{array}$} & \multicolumn{2}{|c|}{$\begin{array}{l}1 \text { isolate per patient, } \\
\text { ICU only }(n=22)\end{array}$} & \multirow{2}{*}{$\begin{array}{l}\text { Meropenem resistant } \\
\text { isolates }(n=30) \\
\% S\end{array}$} \\
\hline & $\% \mathrm{~S}$ & 95\% CI & $\% \mathrm{~S}$ & 95\% CI & \\
\hline Ampicillin-sulbactam & 53.6 & $42.9-64.3$ & 50 & $25.5-74.5$ & 0 \\
\hline Piperacillin-tazobactam & 36 & $28.8-43.2$ & 31.8 & $16.2-47.4$ & 0 \\
\hline Ceftazidime & 45.6 & $36.5-54.7$ & 45.5 & $23.2-67.8$ & 0 \\
\hline Cefepime & 48.8 & $39.0-58.6$ & 36.4 & $18.6-54.2$ & 0 \\
\hline Imipenem & 57.6 & $46.1-69.1$ & 63.6 & $32.4-94.8$ & 0 \\
\hline Meropenem & 54.4 & $43.5-65.2$ & 63.6 & $32.4-94.8$ & 0 \\
\hline Amikacin & 65.5 & $52.4-78.6$ & 68.2 & $34.7-100$ & 33.3 \\
\hline Gentamicin & 53.6 & $42.9-64.3$ & 54.5 & $27.8-81.2$ & 11.5 \\
\hline Tobramycin & 57.6 & $46.1-69.1$ & 59.1 & $30.1-88.1$ & 11.5 \\
\hline Ciprofloxacin & 45.6 & $36.5-54.7$ & 50 & $25.5-74.5$ & 0 \\
\hline Trimethoprim-sulfamethoxazole & 56 & $44.8-67.2$ & 59.1 & $30.1-88.1$ & 17.2 \\
\hline Colistin & 93.6 & $74.9-100$ & 90 & $45.9-100$ & 92.8 \\
\hline Minocycline & 60.9 & $48.7-73.1$ & 57.1 & $29.1-85.1$ & 50.0 \\
\hline
\end{tabular}

Table 4 Example combination antibiogram for 89 isolates of $\mathrm{AB}$ isolated in 2015

\begin{tabular}{llll}
\hline & Amikacin (67.4) & Ciprofloxacin (50.6) & Colistin [89] \\
\hline Ampicillin-sulbactam (56.2) & 67.4 & $59.5^{\mathrm{a}}$ & $95.5^{\mathrm{a}}$ \\
Ceftazidime (50.6) & $71.9^{\mathrm{a}}$ & $55.1^{\mathrm{a}}$ & $96.6^{\mathrm{a}}$ \\
Cefepime (52.8) & $78.6^{\mathrm{a}}$ & $57.3^{\mathrm{a}}$ & $95.5^{\mathrm{a}}$ \\
Meropenem (59.6) & $74.2^{\mathrm{a}}$ & 59.5 & $95.5^{\mathrm{a}}$ \\
\hline
\end{tabular}

Data in parentheses indicate \% of isolates susceptible to antimicrobial on their own, whereas other figures indicate \% of isolates that are susceptible to one or both of the antimicrobials

${ }^{a}$ Isolates for which a higher $\%$ is susceptible to the combination that either agent alone

Alternatively, use of $>1$ year's data can be considered, in particular if year-to-year susceptibility remains fairly stable. Finally, a combination antibiogram can be constructed, which presents data on the percent of isolates that are susceptible to one or both agents in combination (Table 4). This data can be very useful for determining empirical treatment for patients with, or suspected to have, infections caused by Acinetobacter spp.

\section{TREATMENT OF AB INFECTIONS}

The most important facet of treatment for patients infected with $\mathrm{AB}$ is early appropriate antimicrobial therapy. Delays in administration 
of antimicrobial therapy have been associated with increased mortality, and time to appropriate therapy is the strongest modifiable risk factor for poor outcomes of $\mathrm{AB}$ infections [7, 50-52]. Randomized controlled trials are lacking and the optimal antimicrobial treatment for serious $A B$ infections has not been established. B-lactam antibiotics are the preferred antibiotics of choice for susceptible $A B$ infections [53]. Carbapenems have been regarded as the treatment of choice for more resistant isolates, although the incidence of CRAB is increasing. Carbapenem resistance in $\mathrm{AB}$ has been associated with three-fourfold higher mortality during bacteremia and pneumonia, primarily due to delays in time to effective therapy and forcing the use of suboptimal agents for definitive therapy [54-56]. Combination therapy is often recommended for these infections on the premise that it may ensure at least one agent is active in vitro, achieve cidality, improve clinical outcomes, and potentially prevent the emergence of resistance.

\section{Polymyxins}

The efficacy of colistin (polymyxin E) in severe infections due to $\mathrm{AB}$ has been demonstrated in published reports [57-60], while data on polymyxin $B$ are limited. In a prospective study of 35 episodes of VAP due to MDR AB, 21 patients were treated with intravenous colistin monotherapy as this was the only active agent in vitro [57]. These patients were compared to 14 who received imipenem-cilistatin. The cure rate was identical for both groups at $57 \%$ and VAP-related mortality rates were also similar at $38 \%$ and $35.7 \%$ between colistin and imipenem, respectively. Despite the scarcity of published PK, PD, and clinical outcomes literature on polymyxin B compared to colistin, polymyxin B possesses superior PK properties and may be less nephrotoxic than colistin [61]. Regardless of which polymyxin is used, the optimal dosing remains an enigma [62].

Recent in vitro pharmacodynamic evaluations have suggested aggressive, "front-loaded" polymyxin $\mathrm{B}$ dosing regimens in combination with carbapenems to combat MDR AB strains and suppress the emergence of resistance [63]. A retrospective study evaluated the safety and efficacy of a colistin loading dose, high-dose maintenance regimen in critically ill patients with MDR Gram-negative pneumonia (68\% of whom had $\mathrm{AB}$ ) and found no increase in clinical cure or nephrotoxicity overall when compared to cohort of patients receiving a lower dose regimen without a loading dose [64]. Patients in the high-dosing regimen group did have a significantly higher rate of renal injury as assessed by the risk, injury, failure, Loss of kidney function, and end-stage kidney disease criteria (10\% vs. $37 \%, P=0.03$ ). A recent review of the published PK and clinical data regarding the utility of a loading dose of colistin found that, despite the theoretical PK benefit, data from randomized controlled trials are lacking while data from observational studies do not support the use of loading doses. To add to the confusion, the latest in vitro hollow fiber infection model work has demonstrated a paradoxical effect in which higher polymyin $\mathrm{B}$ exposures dramatically increased the isolation of resistant subpopulations of $\mathrm{AB}$ that grew on plates containing $10 \mathrm{mg} / \mathrm{L}$ of polymyxin B [65]. These high exposures also proliferated polymyxin-dependent growth of $\mathrm{AB}$. These experiments were carried out under high bacterial inoculums and without the benefit of the mammalian immune system, so the clinical impact of these findings remains to be determined, although this work contributes to the notion that the polymyxins should preferentially be given as part of a combination therapy against $\mathrm{AB}$.

\section{Tetracyclines}

Minocycline was first introduced in the 1960s and maintains excellent in vitro activity against $\mathrm{AB}$, including isolates that are MDR, and has been used successfully clinically in several small case series. Minocycline is FDA approved for infections due to Acinetobacter, both an intravenous and oral formulation are available for use, and toxicity after short-term use remains minimal. The parenteral minocycline product was also reformulated and FDA approved under the Qualified Infectious Disease Product by The 
Medicines Company in April 2015 [66]. This reformulated product (previously RPX-602) incorporates magnesium sulfate which allows intravenous minocycline to be administered in smaller volumes of fluid and may improve tolerability. Minocycline often retains antimicrobial activity even against $\mathrm{AB}$ strains resistant to other tetracyclines and glycyclines, although cross-resistance exists. It is important that doxycycline not be used as a surrogate for minocycline susceptibilities, as resistance rates are significantly higher for doxycycline. In a recent study of 107 CRAB isolates, minocycline susceptibility rates were approximately 49\% higher than for doxycycline [67]. Several studies have demonstrated the efficacy and safety of minocycline for serious infections due to $A B$. Minocycline has been used successfully in the literature to treat VAP due to $\mathrm{AB}$ [68] and CRAB [69]. The details of these studies have been summarized by Ritchie et al. [70]. Doxycycline retains some in vitro activity against $A B$ but less than that of minocycline and has been rarely used for $A B$ infections. Falagas et al. recently reviewed the use of doxycycline and minocycline for infections due to $\mathrm{AB}$ [71]. They included 10 retrospective studies comprising 156 patients, $65.4 \%$ of which had respiratory infections and $13 \%$ bacteremia. Clinical success was achieved in $76.9 \%$ of patients with microbiological eradication in $71.3 \%$. Adverse events were reported in only 1 of 88 cases. The utility of intravenous minocycline in the modern era of widespread bacterial resistance has also been reviewed in detail by Colton et al. [72] and Greig and Scott [73].

Tigecycline, a semisynthetic glycylcyline derivative of minocycline, also maintains excellent in vitro activity and has been used successfully both alone and in combination with colistin for $\mathrm{AB}$ infections [74]. Worldwide, over $90 \%$ of $\mathrm{AB}$ isolates are susceptible to tigecycline [75, 76], although the data demonstrating the clinical efficacy of tigecycline for the treatment of $\mathrm{AB}$ infections are plagued by high mortality rates, emergence of resistance while on therapy, and frequent adverse events [77-80]. A large, retrospective study examined 266 patients with XDR AB treated with tigecycline alone or in combination and compared them to 120 patients treated with imipenem-cilastatin and sulbactam [81]. Thirty-day mortality rates were high but similar between the groups $(44.7 \%$ vs. $46.7 \%)$. One prospective multicenter Phase III trial compared tigecycline to imipenem-cilastatin for patients with VAP due to $A B$ and found lower cure rates in the tigecycline group (68\% vs. 78\%) [82]. Another retrospective study in ICU patients with pneumonia due to MDR AB matched 84 patients receiving tigecycline to 84 receiving colistin [83]. In this study, mortality was significantly higher among patients receiving tigecycline with a tigecycline MIC of $>2 \mathrm{mg} / \mathrm{L}$ ( $44 \%$ vs. $60.7 \%, P=0.04$ ). Several studies have confirmed the relevance of the in vitro breakpoint of $\geq 2 \mathrm{mg} / \mathrm{L}$ for tigecycline, demonstrating higher mortality when tigecycline MICs were $\geq 2 \mathrm{mg} / \mathrm{L}$, even when tigecycline was used as part of a combination regimen $[83,84]$. Some retrospective studies have demonstrated adequate clinical and microbiologic outcomes with tigecycline, although it was given as part of a combination therapy in almost all cases [85-87].

\section{Ampicillin/Sulbactam}

Sulbactam is a penicillanic acid sulfone $\beta$-lactamase inhibitor with intrinsic in vitro activity against $A B$, although MICs have shown a steady increase over the last decade [76]. Ampicillin-sulbactam has demonstrated similar results to imipenem-cilastatin when treating severe $\mathrm{AB}$ infections, including $\mathrm{VAP}$, in small case series, and was more effective than the polymyxins in treating $\mathrm{CRAB}$ infections [88-90]. It has demonstrated similar clinical and microbiologic outcomes to colisin for MDR $A B$ VAP with less nephrotoxicity [91]. A recent retrospective study from Taiwan reviewed patients who received sulbactam alone or ampicillin-sulbactam for the treatment of pneumonia due to MDR AB [92]. Forty-five patients received sulbactam compared to 125 who received ampicillin-sulbactam, although $79.8 \%$ of patients received combination therapy primarily with a carbapenem $(86.2 \%)$. Clinical resolution of pneumonia occurred in $67.6 \%$ of 
patients with $69 \%$ demonstrating microbiological eradication of $\mathrm{AB}$ from the airways. The 30 -day mortality rate was $31.2 \%$, and independent predictors of clinical failure on multivariate analysis included malignancy, bilateral pneumonia, and shorter duration of therapy. The latest retrospective observational study examined patients with infections due to $A B$ treated with ampicillin-sulbactam or an alternative $\beta$-lactam for at least $72 \mathrm{~h}$ [93]. Of the 69 patients included, 33 received ampicillin-sulbactam and 36 received an alternative $\beta$-lactam (primarily cefepime), and most had a respiratory source of infection. Approximately $20 \%$ of patients received combination therapy with colistin or tigeycline in the amnpicillin-sulbactam group. There were no significant differences in baseline demographics between the groups including source of infection and severity of illness. Clinical cure was similar between the groups $(78.8 \%$ ampicillin-sulbactam vs $72.2 \% \beta$-lactam, $P=\mathrm{NS}$ ), along with length of stay and mortality. Finally, a retrospective study of 168 patients comparing tigecycline-based versus sulbactam-based antimicrobial regimens for the treatment of MDR $\mathrm{AB}$ pneumonia found identical rates of clinical resolution (66.7\%), similar mortality, but a lower rate of microbiological eradication in the tigecycline-based group $(26.2 \%$ vs. $63.5 \%, P<0.05)$ [94].

Similar to the polymyxins, ampicillin-sulbactam is likely most effective as part of a combination regimen against $\mathrm{AB}$, and optimal dosing remains unclear. Case series and observational studies have demonstrated the efficacy of the combination of ampicillin and sulbactam against $\mathrm{AB}$ infections, including bacteremia $[88,89,95-97]$. When the $A B$ isolate is susceptible to ampicillin-sulbactam, the efficacy appears to be comparable to other agents including carbapenems and polymyxins $[90,98]$. Population PK studies with Monte Carlo simulations have demonstrated that, at typical ampicillin-sulbactam doses of 3 g every $8 \mathrm{~h}$, a probability of target attainment (PTA) of 90 of $40 \%$ time above the MIC can only be achieved using a 4-h infusion and only for pathogens with an MIC $\leq 2 \mathrm{mg} / \mathrm{L}$ [99]. Even at $12 \mathrm{~g}$ every $8 \mathrm{~h}$ as a 4 -h infusion, a PTA of $90 \%$ could only be achieved for pathogens with an MIC $\leq 8 \mathrm{mg} / \mathrm{L}$. Both of these doses are likely inadequate, as in one study evaluating 121 isolates of $\mathrm{AB}$, the $\mathrm{MIC}_{50}$ and $\mathrm{MIC}_{90}$ for ampicillin sulbactam were $16 / 8$ and $64 / 32 \mathrm{mg} / \mathrm{L}$, respectively [100]. In a clinical study, Betrosian et al. randomized 27 patients with MDR AB VAP to receive a total daily dose of either 27 or $36 \mathrm{~g}$ of ampicillin-sulbactam divided every $8 \mathrm{~h}$ and demonstrated no significant differences in clinical improvement or bacteriologic success [101]. Importantly, there were no major adverse events reported with this high-dosing scheme.

\section{Aminoglycosides}

Amikacin and tobramycin remain the most active in vitro agents against $\mathrm{AB}$ among the aminoglycosides. It is important to be mindful of susceptibility differences based on the methods used for testing against aminoglycosides against $A B$ [102], as significant discordance has been reported. Aminoglycosides are falling out of favor for the treatment of MDR Gram-negative infections in general due to their high toxicity, lack of efficacy, low tissue penetration, ambiguous synergy, and the availability of more active, less toxic agents [103, 104]. As a general rule, aminoglycosides should not be used as monotherapy for $\mathrm{AB}$, as they demonstrate rapid regrowth and persistence in vitro and poor clinical outcomes [103, 105, 106], although one small study from South Africa demonstrated similar toxicity and clinical outcomes of tobramycin compared to colistin when treating 32 patients with $\mathrm{AB}$ infections [107].

\section{Rifampin}

Rifampin has demonstrated activity against MDR AB in vitro and in in vivo animal models, although two randomized controlled trials failed to show improved outcomes with the addition of rifampin to colistin versus colistin alone for infections due to $\mathrm{AB}[108,109]$.

\section{COMBINATION THERAPY}

The wealth of in vitro data suggests that combination therapy should be beneficial for the 
treatment of serious infections due to $A B$ $[110,111]$. This includes utilizing carbapenems in combination for CRAB, although clinical reports have not always upheld the in vitro data $[112,113]$. The published results are not conclusive and may be disease state-dependent, as combination therapy has demonstrated improved rates of 14 day survival and microbiological eradication for $A B$ bacteremia [114], but failed to show a benefit in patients with $A B$ sepsis [115]. The combination of colistin plus rifampin for serious infections due to $A B$ has failed to demonstrate improved outcomes in two clinical trials and a systematic review [108, 109, 116]. A meta-analysis also concluded that there was no clear benefit to combination therapy for MDR, XDR, or PDR AB infections [71].

The heterogeneity of combination therapies used in the literature for $A B$ infections is broad but often includes colistin a part of the combination approach. Unfortunately, the vast majority of the literature on combination therapies with colistin is in vitro in nature [23]. Colistin combination therapy has shown improved outcomes over colistin monotherapy for patients with $\mathrm{AB}$ bacteremia, although no specific combination proved better than another [114]. A study of 101 patients in Spain with MDR AB infections contrasts these results and found no significant difference in 30-day mortality between combination and monotherapy [115]. A contemporary study found no advantage of colistin combination therapy for $\mathrm{AB}$ VAP in critically ill patients [117]. The combination of colistin and glycopeptides has demonstrated synergy in vitro, although two clinical studies are conflicting in terms of clinical outcomes [118, 119]. A recently published review examined the in vitro and in vivo data regarding synergy of polymyxin combinations and concluded that limitations in current clinical studies (retrospective design, small sample sizes) preclude the translation of even well-executed in vitro experiments [120]. Two clinical trials are underway in the US and Europe (NCT01732250, NCT01597973) comparing colistin monotherapy to colistin plus meropenem, which may provide insight into some of the ambiguity surrounding combination therapy for $\mathrm{AB}$.

A recent study examined the correlation between in vitro checkerboard and time-kill synergy and clinical outcomes in patients infected with XDR AB [121]. In this study, colistin with minocycline produced the highest rate of synergy in vitro via checkerboard assay, although only $6.6 \%$ of wells tested demonstrated synergy which was equal to that of doripenem-colistin-minocycline. Tigecycline-colistin showed a $13.2 \%$ rate of antagonism while minocycline and colistin was bactericidal against $100 \%$ of the 5 isolates tested via time-kill. Patients who received a combination that demonstrated inhibition of growth in vitro demonstrated improved microbiological outcomes.

A retrospective study among critically ill patients with MDR Gram-negative pneumonia, the majority of whom had $A B$ isolated, demonstrated that colistin combination therapy did not improve clinical cure but did significantly improved microbiological cure $(87 \%$ vs. $35.5 \%, P<0.001)$ [122]. Tigeycycline was the most common combination agent $(51.2 \%)$ followed by minocycline $(12.2 \%)$. A post hoc analysis of only patients with $\mathrm{AB}$ pneumonia demonstrated no significant differences in clinical cure, even after multivariate analysis, but again demonstrated a higher rate of microbiological eradication for the 44 patients with repeat cultures available.

A particularly interesting study examined the outcomes of 101 critically ill patients with infections due to $\mathrm{AB}(n=83)$ or $P$. aeruginosa $(n=18)$ who received either polymyxin B monotherapy or polymyxin B in combination with another agent that lacked in vitro activity [123]. Combination therapy consisted primarily of polymyxin B plus meropenem. The 30-day mortality rate in the combination therapy group was significantly lower than that of the monotherapy group $(42.4 \%$ vs. $67.6 \%, P=0.03)$ despite the lack of in vitro activity and combination therapy was independently associated with lower 30-day mortality upon Cox proportional hazards modeling along with normal renal function. These differences remained after 
a propensity score adjustment was made to account for the likelihood of receiving combination therapy. Given that all isolates but one in this study were considered highly carbapenem-resistant (MIC $>32 \mathrm{mg} / \mathrm{L}$ ), it is likely that some degree of synergy was occurring in vivo and that there may be a benefit to combination therapy regardless of susceptibility profiles.

A prospective observational study of patients with sepsis due to MDR $A B$ who received active mono- or combination therapy included 68 patients who received monotherapy and 33 who received combination therapy. A propensity score was used to account for bias in receiving combination therapy. The primary infection was pneumonia, primarily VAP, and colistin was used most often as monotherapy (67.6\%) followed by carbapenems (14.7\%). Colistin plus tigeycline was the most common combination therapy, although this accounted for only $27.3 \%$ of cases and the remaining combination regimens were very heterogeneous including carbapenem plus tigecycline. There was no significant difference in all-cause 30-day mortality between the groups on univariate or multivariate analyses [115].

\section{ANTIMICROBIAL STEWARDSHIP PRINCIPLES}

Controlling the morbidity and mortality associated with $\mathrm{AB}$ requires a multifaceted approach including early detection and identification, strategies for patient risk factor identification, infection control practices, and antimicrobial stewardship surveillance and intervention.

A robust infection prevention program is crucial to help curb the introduction and spread of $\mathrm{AB}$ throughout a healthcare system. The primary goals of infection prevention as they relate to $\mathrm{AB}$ are early recognition and containment. Identifying high-risk patients and those colonized with $\mathrm{AB}$ is vital, as previous colonization with $\mathrm{CRAB}$ has been associated with infection due to CRAB [124]. Despite the obvious advantages of identifying patients who are colonized with $A B$, particularly $M D R A B$, surveillance culturing is not often implemented due to significant logistic and practical challenges. Surveillance cultures, especially from a single site, have demonstrated low sensitivity and require considerable labor and time commitment from hospital and microbiology staff [10]. Specific microbiology laboratory media such as CHROMagar $^{\mathrm{TM}}$ can assist in this process by rapidly and accurately identifying CRAB. The CDC recommends active microbiological surveillance for patients at high risk of colonization with resistant Gram-negative organisms and contact precautions. Cohorting, improved hand hygiene, and enhanced environmental cleaning have been successful at reducing hospital infection rates and controlling outbreaks of $A B$ [125-127].

A multinational task force on the management and prevention of $\mathrm{AB}$ infections in the ICU was recently established [128]. The goal of the task force was to provide clinicians with clear and practical recommendations to optimize therapy and establish infection control measures to eradicate $\mathrm{AB}$. Among the processes endorsed in the document, the group recommends that $A B$ should be routinely identified to the species level by the clinical microbiology laboratory in order to differentiate it from other Acinetobacter spp. outside the $\mathrm{AB}$ group which are only rarely known to cause human disease. Additionally, AB bacteremia has been associated with higher mortality than $A$. nosocomialis or $A$. pitti bacteremia [129] and it is important to correctly associate antibiotic resistant rates with the appropriate species for epidemiologic purposes.

Antimicrobial stewardship programs (ASPs) play an important role in the management of MDR AB infections. Among many important interventions, ASPs can assist in the selection of appropriate agents for the treatment of $\mathrm{AB}$ based on the institutional antibiogram along with an appropriate duration and deescalation of therapy once susceptibility reports are known. Limiting the use of broad spectrum antimicrobial therapy is vitally important, particularly in the treatment of $\mathrm{AB}$, as the use of carbapenems has been linked with increased incidence of CRAB [130], while restricting carpabenem use in the ICU has demonstrated a twofold decrease in the incidence of CRAB 
[131]. ASPs can also support the implementation of rapid diagnostic testing (RDT) in order to more quickly identify $\mathrm{AB}$ and its resistant mechanisms in order to assist in infection control and optimize patient outcomes.

In the only published RDT and ASP intervention study to incorporate non-blood isolates, Wenzler et al. evaluated the use of MALDI-TOF and ASP intervention in patients with pneumonia and/or bacteremia due to $\mathrm{AB}$ [132]. This study was unique in the fact that it capitalized on the weakness of MALDI-TOF. By selecting to study a specific pathogen that is inherently MDR a majority of the time, the identification of $\mathrm{AB}$ by MALDI-TOF allowed for a rapid change in empiric antimicrobial therapy prior to susceptibility results being available. In this quasi-experimental study, 66 patients were included in the pre-intervention group and 53 in the intervention group. The pre-intervention group consisted of traditional microbiological methods and standard existing stewardship interventions, while the intervention group utilized MALDI-TOF to identify AB and targeted stewardship interventions to provide appropriate antimicrobial therapy. Importantly, in this study, patients who were already on effective therapy (defined as any antimicrobial agent with in vitro susceptibility) at the time of MALDI-TOF identification were excluded in order to assess the true impact of ASP intervention. The combination of MALDI-TOF and ASP in patients with pneumonia and/or bacteremia due to $\mathrm{AB}$ significantly reduced the time to effective therapy by over $40 \mathrm{~h}$ and also significantly improved clinical cure at 7 days in the intervention group ( $34 \%$ vs. $15 \%, P=0.016)$. No significant differences in mortality or costs were observed, although MALDI-TOF plus ASP decreased the median infection-related length of stay in the intervention group (13 vs 11 days).

An ASP-driven study also evaluated the safety and effectiveness of minocycline for patients with infections due to MDR AB [133]. The ASP program recommended the addition of intravenous minocycline to formulary after an examination of susceptibility rates revealed that it was the third most susceptible agent behind the polymyxins and tigecycline, and was active against four of the six tigecycline-resistant strains tested. After addition to formulary, the ASP then conducted a retrospective evaluation of the use of minocycline for patients with serious MDR AB infections. A total of 55 critically ill patients (median APACHE II score 21) were evaulated and the primary site of infection was the respiratory tract in 58\% of patients followed by the bloodstream (18\%). The majority of infections were hospital-acquired and clinical success was achieved in $73 \%$ of patients with presumed or documented microbiological eradication in $78 \%$. A quarter of the patients died from their infection and the median length of stay was 30 days. Only 3 patients received minocycline as monotherapy in this study, while the most common agent used in combination was colistin [19], but there were 10 other heterogeneous combination regimens used for the remaining 33 patients. There were no documented adverse events related to the use of minocycline.

\section{PIPELINE AGENTS WITH ACTIVITY AGAINST AB}

There are several agents in the drug development pipeline with promising in vitro activity and innovative mechanisms of action, although their place in therapy and effectiveness for infections due to $A B$ remains to be established. Future non-antibacterial treatment options for $\mathrm{AB}$ have been recently reviewed by Wong et al. [53].

\section{Bal30072}

BAL30072 is a novel dihydroxypyridone monobactam siderophore $\beta$-lactam that permeates Gram-negative bacteria via non-poribased routes involved in iron transport that may allow it to escape resistance mechanisms that compromise other $\beta$-lactams. BAL30072 has demonstrated activity in vitro against OXA-23-producing $\mathrm{AB}$, with $73 \%$ of 200 isolates susceptible at $1 \mathrm{mg} / \mathrm{L}$ [134]. Against MDR AB, it has demonstrated an $\mathrm{MIC}_{90}$ of $4 \mathrm{mg} / \mathrm{L}$ to isolates with a meropenem $\mathrm{MIC}_{90}$ of $>32 \mathrm{mg} / \mathrm{L}$, 
while its in vitro susceptibility against CRAB is comparable to tigecycline [135]. Importantly, BAL30072 also demonstrated activity against MBL-producing $\mathrm{AB}$, including those strains resistant to aztreonam [136]. This molecule has also been shown to decrease meropenem MICs two-eightfold and produce synergy in in vitro time-kill assays, although in vivo efficacy was suboptimal in a rat soft tissue infection model [137]. Conversely in a murine septicemia model, in vitro synergy of BAL30072 and meropenem did translate into improved efficacy in vivo [138]. The addition of $\beta$-lactamase inhibitors does not improve the activity of BAL30072 against AB [139], but sub-MIC concentrations of colistin have been shown to decrease the MIC fourfold in $82 \%$ of $\mathrm{AB}$ isolates. Reduced susceptibility of $\mathrm{AB}$ to BAL30072 in vitro has been correlated to adeb expression [140].

\section{S-649266}

Another novel parenteral siderophore cephalosporin antibiotic, S-649266, has been evaluated in vitro against 104 strains of $\mathrm{AB}$. This compound demonstrated $\mathrm{MIC}_{50}$ and $\mathrm{MIC}_{90}$ values of 0.125 and $2 \mathrm{mg} / \mathrm{L}$, respectively, compared to $>16$ and $>16 \mathrm{mg} / \mathrm{L}$ for meropenem. It also demonstrated excellent activity against carbapenemase-producing strains, including MBL-producers [141]. A multicenter, randomized, open-label clinical study comparing S-649266 to best available therapy for the treatment of severe infections caused by carbapenem-resistant Gram-negative pathogens is currently recruiting (NCT02714595).

\section{Plazomicin}

Plazomicin is a next-generation aminoglycoside ("neoglycoside") with extended activity over other aminoglycosides against some Gram-positive and -negative pathogens. Against $407 \mathrm{AB}$ organisms isolated from 15 hospitals in New York, plazomicin demonstrated $\mathrm{MIC}_{50}$ and $\mathrm{MIC}_{90}$ values of 8 and $16 \mathrm{mg} / \mathrm{L}$, respectively, compared to $32-64$ and $>64 \mathrm{mg} / \mathrm{L}$ for all other aminoglycosides tested [142]. Plazomicin achieved synergy in combination with meropenem or imipenem against 69 imipenem-resistant $\mathrm{AB}$ isolates from Spain. $\mathrm{MIC}_{90}$ values were lower than the other aminoglcyosides, carbapenems, and fosfomycin against CRAB, but higher than colistin or tigecycline MICs [143]. Overall, the in vitro activity of plazomicin appears comparable to that of amikacin, and this drug will come with the same clinical downsides as traditional aminoglycosides, as discussed earlier.

\section{Omadacycline}

Omadacycline is a novel aminomethycycline antibiotic similar to the tetracycline class but with the ability to circumvent typical tetracycline resistance mechanisms. It has demonstrated $\mathrm{MIC}_{50}$ and $\mathrm{MIC}_{90}$ values of 0.025 and $4 \mathrm{mg} / \mathrm{L}$, respectively, to $\mathrm{AB}$ [144] and excellent activity against 5 NDM and 39 OXA-producing isolates.

\section{Eravacycline}

Eravacycline is a novel synthetic fluorocycline similar to the tetracyclines with broad anti-Gram-positive and -negative activity [145]. Against tigecycline and carbapenem-resistant $\mathrm{AB}$ from the UK, eravacycline MICs were approximately twofold lower than that of tigecycline. Importantly, eravacycline retains activity against most high-level minocycline-resistant $\mathrm{AB}$ isolates.

\section{SUMMARY}

$\mathrm{AB}$ has become one of the most unpredictable and difficult to treat pathogens over the last 20 years, aided by its numerous mechanisms of resistance. Empiric antibiotic selection should be based on specific local susceptibility data when available. Specific therapy of $A B$ infection is confounded by the lack of cAST with limited breakpoint interpretations for $\mathrm{AB}$. The use of RUO testing methods can be problematic. Previously, carbapenems were regarded as the drugs of choice for $\mathrm{AB}$ infections, 
although the incidence of CRAB is increasing. Currently, the polymyxins have become increasingly used, but concerns about dosing, $\mathrm{PK} / \mathrm{PD}$, and toxicities have limited their utilization. Among the tetracyclines, only minocycline is included in automated cAST, has FDA-cleared breakpoints, and has reliable in vitro activity against $A B$. Combination therapy for serious infections due to $A B$ is reinforced by in vitro data, although supporting clinical data are inconclusive. Antimicrobial stewardship programs are essential to combat this unpredictable pathogen through use of infection prevention, rapid diagnostics, antibiogram-optimized treatment regimens, and avoidance of carbapenem overuse. The antimicrobial development pipeline includes several agents with in vitro activity against $A B$, but their place in therapy and contribution to the armamentarium against this pathogen remain to be defined.

\section{ACKNOWLEDGEMENTS}

No funding or sponsorship was received for this study or publication of this article. All named authors meet the International Committee of Medical Journal Editors (ICMJE) criteria for authorship for this manuscript, take responsibility for the integrity of the work as a whole, and have given final approval for the version to be published.

Disclosures. Eric Wenzler, Debra A. Goff, Romney Humphries and Ellie J.C. Goldstein declare no conflicts of interest.

Compliance with Ethics Guidelines. This article is based on previously conducted studies and does not involve any new studies of human or animal subjects performed by any of the authors.

Open Access. This article is distributed under the terms of the Creative Commons Attribution-NonCommercial 4.0 International License (http://creativecommons.org/licenses/by-nc/4.0/), which permits any noncommercial use, distribution, and reproduction in any medium, provided you give appropriate credit to the original author(s) and the source, provide a link to the Creative Commons license, and indicate if changes were made.

\section{REFERENCES}

1. Centers for disease control and prevention. Antibiotic resistance threats in the United States. 2013. http://www.cdc.gov/drugresistance/threat-report2013/pdf/ar-threats-2013-508.pdf. Accessed 26 Jan 2015.

2. Boucher HW, Talbot GH, Bradley JS, Edwards JE, Gilbert D, Rice LB, Scheld M, Spellberg B, Bartlett J. Bad bugs, no drugs: no ESKAPE! An update from the infectious diseases society of America. Clin Infect Dis. 2009;48:1-12.

3. Magiorakos AP, Srinivasan A, Carey RB, Carmeli Y, Falagas ME, Giske CG, Harbarth S, Hindler JF, Kahlmeter G, Olsson-Liljequist B, Paterson DL, Rice LB, Stelling J, Struelens MJ, Vatopoulos A, Weber JT, Monnet DL. Multidrug-resistant, extensively drug-resistant and pandrug-resistant bacteria: an international expert proposal for interim standard definitions for acquired resistance. Clin Microbiol Infect. 2012;18:268-81.

4. Nelson RE, Schweizer ML, Perencevich EN, Nelson SD, Khader K, Chiang HY, Chorazy ML, Blevins A, Ward MA, Samore MH. Costs and mortality associated with multidrug-resistant healthcare-associated acinetobacter infections. Infect Control Hosp Epidemiol. 2016;37:1212-8.

5. Clark NM, Zhanel GG, Lynch JP 3rd. Emergence of antimicrobial resistance among Acinetobacter species: a global threat. Curr Opin Crit Care. 2016;22:491-9.

6. Park JH, Choi SH, Chung JW. The impact of early adequate antimicrobial therapy on 14-day mortality in patients with monomicrobial Pseudomonas aeruginosa and Acinetobacter baumannii bacteremia. J Infect Chemother. 2013;19:843-9.

7. Erbay A, Idil A, Gozel MG, Mumcuoglu I, Balaban N. Impact of early appropriate antimicrobial therapy on survival in Acinetobacter baumannii bloodstream infections. Int J Antimicrob Agents. 2009;34:575-9.

8. Doi Y, Murray GL, Peleg AY. Acinetobacter baumannii: evolution of antimicrobial resistance-treatment options. Semin Respir Crit Care Med. 2015;36:85-98. 
9. Wendt C, Dietze B, Dietz E, Ruden H. Survival of Acinetobacter baumannii on dry surfaces. J Clin Microbiol. 1997;35:1394-7.

10. Marchaim D, Navon-Venezia S, Schwartz D, Tarabeia J, Fefer I, Schwaber MJ, Carmeli Y. Surveillance cultures and duration of carriage of multidrug-resistant Acinetobacter baumannii. J Clin Microbiol. 2007;45:1551-5.

11. Mussi MA, Gaddy JA, Cabruja M, Arivett BA, Viale AM, Rasia R, Actis LA. The opportunistic human pathogen Acinetobacter baumannii senses and responds to light. J Bacteriol. 2010;192:6336-45.

12. Peleg AY, de Breij A, Adams MD, Cerqueira GM, Mocali S, Galardini M, Nibbering PH, Earl AM, Ward DV, Paterson DL, Seifert H, Dijkshoorn L. The success of acinetobacter species; genetic, metabolic and virulence attributes. PLoS ONE. 2012;7:e46984.

13. Davis JS, McMillan M, Swaminathan A, Kelly JA, Piera KE, Baird RW, Currie BJ, Anstey NM. A 16-year prospective study of community-onset bacteremic Acinetobacter pneumonia: low mortality with appropriate initial empirical antibiotic protocols. Chest. 2014;146:1038-45.

14. Gaynes R, Edwards JR, National Nosocomial Infections Surveillance $\mathrm{S}$. Overview of nosocomial infections caused by gram-negative bacilli. Clin Infect Dis. 2005;41:848-54.

15. Sader HS, Farrell DJ, Flamm RK, Jones RN. Antimicrobial susceptibility of Gram-negative organisms isolated from patients hospitalized in intensive care units in United States and European hospitals (2009-2011). Diagn Microbiol Infect Dis. 2014;78:443-8.

16. Wisplinghoff $H$, Bischoff $T$, Tallent SM, Seifert $H$, Wenzel RP, Edmond MB. Nosocomial bloodstream infections in US hospitals: analysis of 24,179 cases from a prospective nationwide surveillance study. Clin Infect Dis. 2004;39:309-17.

17. Lob SH, Hoban DJ, Sahm DF, Badal RE. Regional differences and trends in antimicrobial susceptibility of Acinetobacter baumannii. Int J Antimicrob Agents. 2016;47:317-23.

18. Munoz-Price LS, Weinstein RA. Acinetobacter infection. N Engl J Med. 2008;358:1271-81.

19. Jones RN, Guzman-Blanco M, Gales AC, Gallegos B, Castro AL, Martino MD, Vega S, Zurita J, Cepparulo M, Castanheira M. Susceptibility rates in Latin American nations: report from a regional resistance surveillance program (2011). Braz J Infect Dis. 2013;17:672-81.

20. Nordmann P, Picazo JJ, Mutters R, Korten V, Quintana A, Laeuffer JM, Seak JC, Flamm RK, Morrissey I, group Cs. Comparative activity of carbapenem testing: the COMPACT study. J Antimicrob Chemother. 2011;66:1070-8.

21. Queenan AM, Pillar CM, Deane J, Sahm DF, Lynch AS, Flamm RK, Peterson J, Davies TA. Multidrug resistance among Acinetobacter spp. in the USA and activity profile of key agents: results from CAPITAL Surveillance 2010. Diagn Microbiol Infect Dis. 2012;73:267-70.

22. Sievert DM, Ricks P, Edwards JR, Schneider A, Patel J, Srinivasan A, Kallen A, Limbago B, Fridkin S, National Healthcare Safety Network T, Participating NF. Antimicrobial-resistant pathogens associated with healthcare-associated infections: summary of data reported to the national healthcare safety network at the centers for disease control and prevention, 2009-2010. Infect Control Hosp Epidemiol. 2013;34:1-14.

23. Cai Y, Chai D, Wang R, Liang B, Bai N. Colistin resistance of Acinetobacter baumannii: clinical reports, mechanisms and antimicrobial strategies. J Antimicrob Chemother. 2012;67:1607-15.

24. Potron A, Poirel L, Nordmann P. Emerging broad-spectrum resistance in Pseudomonas aeruginosa and Acinetobacter baumannii: mechanisms and epidemiology. Int $\mathrm{J}$ Antimicrob Agents. 2015;45:568-85.

25. Poirel L, Naas T, Guibert M, Chaibi EB, Labia R, Nordmann P. Molecular and biochemical characterization of VEB-1, a novel class A extended-spectrum beta-lactamase encoded by an Escherichia coli integron gene. Antimicrob Agents Chemother. $1999 ; 43: 573-81$.

26. Bonnin RA, Nordmann P, Potron A, Lecuyer H, Zahar JR, Poirel L. Carbapenem-hydrolyzing GES-type extended-spectrum beta-lactamase in Acinetobacter baumannii. Antimicrob Agents Chemother. 2011;55:349-54.

27. Poirel L, Nordmann P. Carbapenem resistance in Acinetobacter baumannii: mechanisms and epidemiology. Clin Microbiol Infect. 2006;12:826-36.

28. Chiu CH, Lee HY, Tseng LY, Chen CL, Chia JH, Su LH, Liu SY. Mechanisms of resistance to ciprofloxacin, ampicillin/sulbactam and imipenem in Acinetobacter baumannii clinical isolates in Taiwan. Int J Antimicrob Agents. 2010;35:382-6.

29. Cornaglia G, Riccio ML, Mazzariol A, Lauretti L, Fontana R, Rossolini GM. Appearance of IMP-1 metallo-beta-lactamase in Europe. Lancet. 1999;353:899-900.

30. Lee K, Lee WG, Uh Y, Ha GY, Cho J, Chong Y, Korean Nationwide Surveillance of Antimicrobial 
Resistance G. VIM- and IMP-type metallo-beta-lactamase-producing Pseudomonas spp. and Acinetobacter spp. in Korean hospitals. Emerg Infect Dis. 2003;9:868-71.

31. Shibata N, Doi Y, Yamane K, Yagi T, Kurokawa H, Shibayama K, Kato H, Kai K, Arakawa Y. PCR typing of genetic determinants for metallo-beta-lactamases and integrases carried by gram-negative bacteria isolated in Japan, with focus on the class 3 integron. J Clin Microbiol. 2003;41:5407-13.

32. Uma Karthika R, Srinivasa Rao R, Sahoo S, Shashikala P, Kanungo R, Jayachandran S, Prashanth K. Phenotypic and genotypic assays for detecting the prevalence of metallo-beta-lactamases in clinical isolates of Acinetobacter baumannii from a South Indian tertiary care hospital. J Med Microbiol. 2009;58:430-5.

33. Lee K, Yum JH, Yong D, Lee HM, Kim HD, Docquier JD, Rossolini GM, Chong Y. Novel acquired metallo-beta-lactamase gene, bla(SIM-1), in a class 1 integron from Acinetobacter baumannii clinical isolates from Korea. Antimicrob Agents Chemother. 2005;49:4485-91.

34. Zhou Z, Du X, Wang L, Yang Q, Fu Y, Yu Y. Clinical carbapenem-resistant Acinetobacter baylyi strain coharboring blaSIM-1 and blaOXA-23 from China. Antimicrob Agents Chemother. 2011;55:5347-9.

35. Bonnin RA, Poirel L, Nordmann P. New Delhi metallo-beta-lactamase-producing Acinetobacter baumannii: a novel paradigm for spreading antibiotic resistance genes. Future Microbiol. 2014;9:33-41.

36. Rodriguez-Martinez JM, Nordmann P, Ronco E, Poirel L. Extended-spectrum cephalosporinase in Acinetobacter baumannii. Antimicrob Agents Chemother. 2010;54:3484-8.

37. Tian GB, Adams-Haduch JM, Taracila M, Bonomo RA, Wang HN, Doi Y. Extended-spectrum AmpC cephalosporinase in Acinetobacter baumannii: aDC-56 confers resistance to cefepime. Antimicrob Agents Chemother. 2011;55:4922-5.

38. Magnet S, Courvalin P, Lambert T. Resistance-nodulation-cell division-type efflux pump involved in aminoglycoside resistance in Acinetobacter baumannii strain BM4454. Antimicrob Agents Chemother. 2001;45:3375-80.

39. Rumbo C, Gato E, Lopez M, Ruiz de Alegria C, Fernandez-Cuenca F, Martinez-Martinez L, Vila J, Pachon J, Cisneros JM, Rodriguez-Bano J, Pascual A, Bou G, Tomas M, Spanish Group of Nosocomial I, Mechanisms of A, Resistance to A, Spanish Society of Clinical M, Infectious D, Spanish Network for Research in Infectious D. Contribution of efflux pumps, porins, and beta-lactamases to multidrug resistance in clinical isolates of Acinetobacter baumannii. Antimicrob Agents Chemother. 2013;57:5247-57.

40. Beceiro A, Llobet E, Aranda J, Bengoechea JA, Doumith M, Hornsey M, Dhanji H, Chart H, Bou G, Livermore DM, Woodford N. Phosphoethanolamine modification of lipid A in colistin-resistant variants of Acinetobacter baumannii mediated by the pmrAB two-component regulatory system. Antimicrob Agents Chemother. 2011;55:3370-9.

41. Moffatt JH, Harper M, Harrison P, Hale JD, Vinogradov E, Seemann T, Henry R, Crane B, St Michael F, Cox AD, Adler B, Nation RL, Li J, Boyce JD. Colistin resistance in Acinetobacter baumannii is mediated by complete loss of lipopolysaccharide production. Antimicrob Agents Chemother. 2010;54:4971-7.

42. Girardello R, Visconde M, Cayo R, Figueiredo RC, Mori MA, Lincopan N, Gales AC. Diversity of polymyxin resistance mechanisms among Acinetobacter baumannii clinical isolates. Diagn Microbiol Infect Dis. 2017;87:37-44.

43. Humphries RM, Hindler JA. Emerging resistance, new antimicrobial agents ... but no tests! the challenge of antimicrobial susceptibility testing in the current us regulatory landscape. Clin Infect Dis. 2016;63:83-8.

44. CLSI. Performance standards for antimicrobial susceptibility testing, vol M100S. 26th ed. Wayne: Clinical and Laboratory Standards Institute; 2016.

45. Heil EL, Johnson JK. Impact of CLSI breakpoint changes on microbiology laboratories and antimicrobial stewardship programs. J Clin Microbiol. 2016;54:840-4.

46. Wang P, Bowler SL, Kantz SF, Mettus RT, Guo Y, McElheny CL, Doi Y. Comparison of minocycline susceptibility testing methods for carbapenem-resistant Acinetobacer baumannii. J Clin Microbiol. 2016. (01810-16 Epub ahead of print).

47. Dimitriadis P, Protonotariou E, Varlamis S, Poulou A, Vasilaki O, Metallidis S, Tsakris A, Malisiovas N, Skoura L, Pournaras S. Comparative evaluation of minocycline susceptibility testing methods in carbapenem-resistant Acinetobacter baumannii. In J Antimicrob Agents. 2016;48:321-3.

48. Jerke KH, Lee MJ, Humphries RM. Polymyxin susceptibility testing: a cold case reopened. Clin Microbiol Newsletter. 2016;38:69-77.

49. (EUCAST) ECoAST. Recommendations for MIC determination of colistin (polymyxin E) as 
recommended by the joint CLSI-EUCAST polymyxin breakpoints working group. 2016. http:// www.eucast.org/fileadmin/src/media/PDFs/EUCAST _files/General_documents/Recommendations_for_ MIC_determination_of_colistin_March_2016pdf Accessed 21 No $201 \overline{6}$.

50. Grupper M, Sprecher H, Mashiach T, Finkelstein R. Attributable mortality of nosocomial Acinetobacter bacteremia. Infect Control Hosp Epidemiol. 2007;28:293-8.

51. Robenshtok E, Paul M, Leibovici L, Fraser A, Pitlik S, Ostfeld I, Samra Z, Perez S, Lev B, Weinberger M. The significance of Acinetobacter baumannii bacteraemia compared with Klebsiella pneumoniae bacteraemia: risk factors and outcomes. J Hosp Infect. 2006;64:282-7.

52. Sunenshine RH, Wright MO, Maragakis LL, Harris AD, Song X, Hebden J, Cosgrove SE, Anderson A, Carnell J, Jernigan DB, Kleinbaum DG, Perl TM, Standiford HC, Srinivasan A. Multidrug-resistant Acinetobacter infection mortality rate and length of hospitalization. Emerg Infect Dis. 2007;13:97-103.

53. Wong D, Nielsen TB, Bonomo RA, Pantapalangkoor P, Luna B, Spellberg B. Clinical and pathophysiological overview of acinetobacter infections: a century of challenges. Clin Microbiol Rev. 2017;30:409-47.

54. Lemos EV, de la Hoz FP, Einarson TR, McGhan WF, Quevedo E, Castaneda C, Kawai K. Carbapenem resistance and mortality in patients with Acinetobacter baumannii infection: systematic review and meta-analysis. Clin Microbiol Infect. 2014;20:416-23.

55. Liu CP, Shih SC, Wang NY, Wu AY, Sun FJ, Chow SF, Chen TL, Yan TR. Risk factors of mortality in patients with carbapenem-resistant Acinetobacter baumannii bacteremia. J Microbiol Immunol Infect. 2014; doi:10.1016/j.jmii.2014.10.006.

56. Nutman A, Glick R, Temkin E, Hoshen M, Edgar R, Braun T, Carmeli Y. A case-control study to identify predictors of 14-day mortality following carbapenem-resistant Acinetobacter baumannii bacteraemia. Clin Microbiol Infect. 2014;20:O1028-34.

57. Garnacho-Montero J, Ortiz-Leyba C, Jimenez-Jimenez FJ, Barrero-Almodovar AE, Garcia-Garmendia JL, Bernabeu-Wittel IM, Gallego-Lara SL, Madrazo-Osuna J. Treatment of multidrug-resistant Acinetobacter baumannii ventilator-associated pneumonia (VAP) with intravenous colistin: a comparison with imipenem-susceptible VAP. Clin Infect Dis. 2003;36:1111-8.

58. Kallel H, Hergafi L, Bahloul M, Hakim A, Dammak H, Chelly H, Hamida CB, Chaari A, Rekik N, Bouaziz
M. Safety and efficacy of colistin compared with imipenem in the treatment of ventilator-associated pneumonia: a matched case-control study. Intensive Care Med. 2007;33:1162-7.

59. Levin AS, Barone AA, Penco J, Santos MV, Marinho IS, Arruda EA, Manrique EI, Costa SF. Intravenous colistin as therapy for nosocomial infections caused by multidrug-resistant Pseudomonas aeruginosa and Acinetobacter baumannii. Clin Infect Dis. 1999;28:1008-11.

60. Reina R, Estenssoro E, Saenz G, Canales HS, Gonzalvo R, Vidal G, Martins G, Das Neves A, Santander $\mathrm{O}$, Ramos C. Safety and efficacy of colistin in Acinetobacter and Pseudomonas infections: a prospective cohort study. Intensive Care Med. 2005;31:1058-65.

61. Nation RL, Velkov T, Li J. Colistin and polymyxin B: peas in a pod, or chalk and cheese? Clin Infect Dis. 2014;59:88-94.

62. Pogue JM, Ortwine JK, Kaye KS. Colistin dosing: does the fun ever start? Clin Infect Dis. 2016. doi:10.1093/cid/ciw685.

63. Rao GG, Ly NS, Bulitta JB, Soon RL, San Roman MD, Holden PN, Landersdorfer CB, Nation RL, Li J, Forrest A, Tsuji BT. Polymyxin B in combination with doripenem against heteroresistant Acinetobacter baumannii: pharmacodynamics of new dosing strategies. J Antimicrob Chemother. 2016; doi:10. 1093/jac/dkw293.

64. Elefritz Jl, Bauer KA, Jones C, Mangino JE, Porter K, Murphy CV. Efficacy and safety of a colistin loading dose, high-dose maintenance regimen in critically ill patients with multidrug-resistant gram-negative pneumonia. Intensive Care Med. 2016; doi:10. $1177 / 0885066616646551$.

65. Tsuji BT, Landersdorfer CB, Lenhard JR, Cheah SE, Thamlikitkul V, Rao GG, Holden PN, Forrest A, Bulitta JB, Nation RL, Li J. Paradoxical effect of polymyxin b: high drug exposure amplifies resistance in Acinetobacter baumannii. Antimicrob Agents Chemother. 2016;60:3913-20.

66. The medicines company. The medicines company reports first quarter 2015 financial results and operational developments. 2015. http://www. themedicinescompany.com/investors/news/ medicines-company-reports-first-quarter-2015financial-results-and-operational. Accessed 12 Jan 2017.

67. Wang P, Bowler SL, Kantz SF, Mettus RT, Guo Y, McElheny CL, Doi Y. Comparison of minocycline susceptibility testing methods for carbapenem-resistant Acinetobacter baumannii. J Clin Microbiol. 2016;54:2937-41. 
68. Wood GC, Hanes SD, Boucher BA, Croce MA, Fabian TC. Tetracyclines for treating multidrug-resistant Acinetobacter baumannii ventilator-associated pneumonia. Intensive Care Med. 2003;29:2072-6.

69. Chan JD, Graves JA, Dellit TH. Antimicrobial treatment and clinical outcomes of carbapenem-resistant Acinetobacter baumannii ventilator-associated pneumonia. J Intensive Care Med. 2010;25:343-8.

70. Ritchie DJ, Garavaglia-Wilson A. A review of intravenous minocycline for treatment of multidrug-resistant Acinetobacter infections. Clin Infect Dis. 2014;59(Suppl 6):S374-80.

71. Poulikakos P, Tansarli GS, Falagas ME. Combination antibiotic treatment versus monotherapy for multidrug-resistant, extensively drug-resistant, and pandrug-resistant Acinetobacter infections: a systematic review. Eur J Clin Microbiol Infect Dis. 2014;33:1675-85.

72. Colton B, McConeghy KW, Schreckenberger PC, Danziger LH. I.V. minocycline revisited for infections caused by multidrug-resistant organisms. Am J Health Syst Pharm. 2016;73:279-85.

73. Greig SL, Scott LJ. Intravenous minocycline: a review in Acinetobacter infections. Drugs. 2016;76:1467-76.

74. Ku K, Pogue JM, Moshos J, Bheemreddy S, Wang Y, Bhargava A, Campbell M, Khandker N, Lephart PR, Chopra T, Hayakawa K, Martin ET, Abreu-Lanfranco $\mathrm{O}$, Dhar S, Kaye KS, Marchaim D. Retrospective evaluation of colistin versus tigecycline for the treatment of Acinetobacter baumannii and/or carbapenem-resistant Enterobacteriaceae infections. Am J Infect Control. 2012;40:983-7.

75. Sader HS, Farrell DJ, Flamm RK, Jones RN. Antimicrobial susceptibility of Gram-negative organisms isolated from patients hospitalised with pneumonia in US and European hospitals: results from the SENTRY antimicrobial surveillance program, 2009-2012. Int J Antimicrob Agents. 2014;43:328-34.

76. Jones RN, Flonta M, Gurler N, Cepparulo M, Mendes RE, Castanheira M. Resistance surveillance program report for selected European nations (2011). Diagn Microbiol Infect Dis. 2014;78:429-36.

77. Karageorgopoulos DE, Kelesidis T, Kelesidis I, Falagas ME. Tigecycline for the treatment of multidrug-resistant (including carbapenem-resistant) Acinetobacter infections: a review of the scientific evidence. J Antimicrob Chemother. 2008;62:45-55.

78. Poulakou G, Kontopidou FV, Paramythiotou E, Kompoti M, Katsiari M, Mainas E, Nicolaou C, Yphantis D, Antoniadou A, Trikka-Graphakos E,
Roussou Z, Clouva P, Maguina N, Kanellakopoulou K, Armaganidis A, Giamarellou H. Tigecycline in the treatment of infections from multi-drug resistant gram-negative pathogens. J Infect. 2009;58:273-84.

79. Peleg AY, Potoski BA, Rea R, Adams J, Sethi J, Capitano B, Husain S, Kwak EJ, Bhat SV, Paterson DL. Acinetobacter baumannii bloodstream infection while receiving tigecycline: a cautionary report. J Antimicrob Chemother. 2007;59:128-31.

80. Kim NH, Hwang JH, Song KH, Choe PG, Kim ES, Park SW, Kim HB, Kim NJ, Park WB, Oh MD. Tigecycline in carbapenem-resistant Acinetobacter baumannii bacteraemia: susceptibility and clinical outcome. Scand J Infect Dis. 2013;45:315-9.

81. Lee YT, Tsao SM, Hsueh PR. Clinical outcomes of tigecycline alone or in combination with other antimicrobial agents for the treatment of patients with healthcare-associated multidrug-resistant Acinetobacter baumannii infections. Eur J Clin Microbiol Infect Dis. 2013;32:1211-20.

82. Freire AT, Melnyk V, Kim MJ, Datsenko O, Dzyublik O, Glumcher F, Chuang YC, Maroko RT, Dukart G, Cooper CA, Korth-Bradley JM, Dartois N, Gandjini $\mathrm{H}$, Study G. Comparison of tigecycline with imipenem/cilastatin for the treatment of hospital-acquired pneumonia. Diagn Microbiol Infect Dis. 2010;68:140-51.

83. Chuang YC, Cheng CY, Sheng WH, Sun HY, Wang JT, Chen YC, Chang SC. Effectiveness of tigecycline-based versus colistin- based therapy for treatment of pneumonia caused by multidrug-resistant Acinetobacter baumannii in a critical setting: a matched cohort analysis. BMC Infect Dis. 2014;14:102.

84. Cheng A, Chuang YC, Sun HY, Sheng WH, Yang CJ, Liao CH, Hsueh PR, Yang JL, Shen NJ, Wang JT, Hung CC, Chen YC, Chang SC. Excess mortality associated with colistin-tigecycline compared with colistin-carbapenem combination therapy for extensively drug-resistant Acinetobacter baumannii bacteremia: a multicenter prospective observational study. Crit Care Med. 2015;43:1194-204.

85. Gordon NC, Wareham DW. A review of clinical and microbiological outcomes following treatment of infections involving multidrug-resistant Acinetobacter baumannii with tigecycline. J Antimicrob Chemother. 2009;63:775-80.

86. Guner R, Hasanoglu I, Keske S, Kalem AK, Tasyaran MA. Outcomes in patients infected with carbapenem-resistant Acinetobacter baumannii and treated with tigecycline alone or in combination therapy. Infection. 2011;39:515-8.

87. Schafer JJ, Goff DA, Stevenson KB, Mangino JE. Early experience with tigecycline for 
ventilator-associated pneumonia and bacteremia caused by multidrug-resistant Acinetobacter baumannii. Pharmacotherapy. 2007;27:980-7.

88. Levin AS, Levy CE, Manrique AE, Medeiros EA, Costa SF. Severe nosocomial infections with imipenem-resistant Acinetobacter baumannii treated with ampicillin/sulbactam. Int J Antimicrob Agents. 2003;21:58-62.

89. Urban C, Go E, Mariano N, Berger BJ, Avraham I, Rubin D, Rahal JJ. Effect of sulbactam on infections caused by imipenem-resistant Acinetobacter calcoaceticus biotype anitratus. J Infect Dis. 1993;167:448-51.

90. Wood GC, Hanes SD, Croce MA, Fabian TC, Boucher BA. Comparison of ampicillin-sulbactam and imipenem-cilastatin for the treatment of acinetobacter ventilator-associated pneumonia. Clin Infect Dis. 2002;34:1425-30.

91. Betrosian AP, Frantzeskaki F, Xanthaki A, Douzinas EE. Efficacy and safety of high-dose ampicillin/sulbactam vs. colistin as monotherapy for the treatment of multidrug resistant Acinetobacter baumannii ventilator-associated pneumonia. J Infect. 2008;56:432-6.

92. Lin HS, Lee MH, Cheng CW, Hsu PC, Leu HS, Huang CT, Ye JJ. Sulbactam treatment for pneumonia involving multidrug-resistant Acinetobacter calcoaceticus-Acinetobacter baumannii complex. Infect Dis (Lond). 2015;47:370-8.

93. Busey K, Ferreira J, Aldridge P, Johnson D, Guzman N, Jankowski CA. Treatment efficacy of Ampicillin/ Sulbactam in comparison to alternative beta-lactams for severe Acinetobacter baumannii infections. Infect Dis (Lond). 2016;48:775-7.

94. Ye JJ, Lin HS, Yeh CF, Wu YM, Huang PY, Yang CC, Huang CT, Lee MH. Tigecycline-based versus sulbactam-based treatment for pneumonia involving multidrug-resistant Acinetobacter calcoaceticus-Acinetobacter baumannii complex. BMC Infect Dis. 2016;16:374.

95. Jellison TK, McKinnon PS, Rybak MJ. Epidemiology, resistance, and outcomes of Acinetobacter baumannii bacteremia treated with imipenem-cilastatin or ampicillin-sulbactam. Pharmacotherapy. 2001;21:142-8.

96. Smolyakov R, Borer A, Riesenberg K, Schlaeffer F, Alkan M, Porath A, Rimar D, Almog Y, Gilad J. Nosocomial multi-drug resistant Acinetobacter baumannii bloodstream infection: risk factors and outcome with ampicillin-sulbactam treatment. J Hosp Infect. 2003;54:32-8.

97. Corbella X, Ariza J, Ardanuy C, Vuelta M, Tubau F, Sora M, Pujol M, Gudiol F. Efficacy of sulbactam alone and in combination with ampicillin in nosocomial infections caused by multiresistant Acinetobacter baumannii. J Antimicrob Chemother. 1998;42:793-802.

98. Oliveira MS, Prado GV, Costa SF, Grinbaum RS, Levin AS. Ampicillin/sulbactam compared with polymyxins for the treatment of infections caused by carbapenem-resistant Acinetobacter spp. J Antimicrob Chemother. 2008;61:1369-75.

99. Jaruratanasirikul S, Wongpoowarak W, Aeinlang N, Jullangkoon M. Pharmacodynamics modeling to optimize dosage regimens of sulbactam. Antimicrob Agents Chemother. 2013;57:3441-4.

100. Viana GF, Saalfeld SM, Moreira RR, Menegucci TC, Garcia LB, Cardoso CL, Marroni FE, Tognim MC. Can ampicillin/sulbactam resistance in Acinetobacter baumannii be predicted accurately by disk diffusion? J Glob Antimicrob Resist. 2013;1:221-3.

101. Betrosian AP, Frantzeskaki F, Xanthaki A, Georgiadis G. High-dose ampicillin-sulbactam as an alternative treatment of late-onset VAP from multidrug-resistant Acinetobacter baumannii. Scand J Infect Dis. 2007;39:38-43.

102. Akers KS, Chaney C, Barsoumian A, Beckius M, Zera W, Yu X, Guymon C, Keen EF 3rd, Robinson BJ, Mende K, Murray CK. Aminoglycoside resistance and susceptibility testing errors in Acinetobacter baumannii-calcoaceticus complex. J Clin Microbiol. 2010;48:1132-8.

103. Kalil AC, Metersky ML, Klompas M, Muscedere J, Sweeney DA, Palmer LB, Napolitano LM, O'Grady NP, Bartlett JG, Carratalà J, El Solh AA, Ewig S, Fey PD, File TM, Restrepo MI, Roberts JA, Waterer GW, Cruse P, Knight SL, Brozek JL. Management of adults with hospital-acquired and ventilator-associated pneumonia: 2016 clinical practice guidelines by the infectious diseases society of America and the American thoracic society. Clin Infect Dis. 2016. doi:10.1093/cid/ciw353.

104. Paul M, Lador A, Grozinsky-Glasberg S, Leibovici L. Beta lactam antibiotic monotherapy versus beta lactam-aminoglycoside antibiotic combination therapy for sepsis. Cochrane Database Syst Rev. 2014;. doi:10.1002/14651858.CD003344.pub3: CD003344.

105. Vidal L, Gafter-Gvili A, Borok S, Fraser A, Leibovici L, Paul M. Efficacy and safety of aminoglycoside monotherapy: systematic review and meta-analysis of randomized controlled trials. J Antimicrob Chemother. 2007;60:247-57.

106. Michiels JE, Van den Bergh B, Verstraeten N, Fauvart $M$, Michiels J. In vitro emergence of high persistence upon periodic aminoglycoside challenge in 
the ESKAPE pathogens. Antimicrob Agents Chemother. 2016;60:4630-7.

107. Gounden R, Bamford C, van Zyl-Smit R, Cohen K, Maartens G. Safety and effectiveness of colistin compared with tobramycin for multi-drug resistant Acinetobacter baumannii infections. BMC Infect Dis. 2009;9:26.

108. Aydemir H, Akduman D, Piskin N, Comert F, Horuz E, Terzi A, Kokturk F, Ornek T, Celebi G. Colistin vs. the combination of colistin and rifampicin for the treatment of carbapenem-resistant Acinetobacter baumannii ventilator-associated pneumonia. Epidemiol Infect. 2013;141:1214-22.

109. Durante-Mangoni E, Signoriello G, Andini R, Mattei A, De Cristoforo M, Murino P, Bassetti M, Malacarne P, Petrosillo N, Galdieri N, Mocavero P, Corcione A, Viscoli C, Zarrilli R, Gallo C, Utili R. Colistin and rifampicin compared with colistin alone for the treatment of serious infections due to extensively drug-resistant Acinetobacter baumannii: a multicenter, randomized clinical trial. Clin Infect Dis. 2013;57:349-58.

110. Pachon-Ibanez ME, Docobo-Perez F, Lopez-Rojas R, Dominguez-Herrera J, Jimenez-Mejias ME, Garcia-Curiel A, Pichardo C, Jimenez L, Pachon J. Efficacy of rifampin and its combinations with imipenem, sulbactam, and colistin in experimental models of infection caused by imipenem-resistant Acinetobacter baumannii. Antimicrob Agents Chemother. 2010;54:1165-72.

111. Song JY, Kee SY, Hwang IS, Seo YB, Jeong HW, Kim WJ, Cheong HJ. In vitro activities of carbapenem/sulbactam combination, colistin, colistin/ rifampicin combination and tigecycline against carbapenem-resistant Acinetobacter baumannii. J Antimicrob Chemother. 2007;60:317-22.

112. Lee NY, Wang CL, Chuang YC, Yu WL, Lee HC, Chang CM, Wang LR, Ko WC. Combination carbapenem-sulbactam therapy for critically ill patients with multidrug-resistant Acinetobacter baumannii bacteremia: four case reports and an in vitro combination synergy study. Pharmacotherapy. 2007;27:1506-11.

113. Saballs M, Pujol M, Tubau F, Pena C, Montero A, Dominguez MA, Gudiol F, Ariza J. Rifampicin/imipenem combination in the treatment of carbapenem-resistant Acinetobacter baumannii infections. J Antimicrob Chemother. 2006;58:697-700.

114. Batirel A, Balkan II, Karabay O, Agalar C, Akalin S, Alici O, Alp E, Altay FA, Altin N, Arslan F, Aslan T, Bekiroglu N, Cesur S, Celik AD, Dogan M, Durdu B, Duygu F, Engin A, Engin DO, Gonen I, Guclu E, Guven T, Hatipoglu CA, Hosoglu S, Karahocagil
MK, Kilic AU, Ormen B, Ozdemir D, Ozer S, Oztoprak N, Sezak N, Turhan V, Turker N, Yilmaz H. Comparison of colistin-carbapenem, colistin-sulbactam, and colistin plus other antibacterial agents for the treatment of extremely drug-resistant Acinetobacter baumannii bloodstream infections. Eur J Clin Microbiol Infect Dis. 2014;33:1311-22.

115. Lopez-Cortes LE, Cisneros JM, Fernandez-Cuenca F, Bou G, Tomas M, Garnacho-Montero J, Pascual A, Martinez-Martinez L, Vila J, Pachon J, Rodriguez Bano J, Group GER-A. Monotherapy versus combination therapy for sepsis due to multidrug-resistant Acinetobacter baumannii: analysis of a multicentre prospective cohort. J Antimicrob Chemother. 2014;69:3119-26.

116. Al-Shaer M, Nazer LH, Kherallah M. Rifampicin as adjunct to colistin therapy in the treatment of multidrug-resistant Acinetobacter baumannii. Ann Pharmacother. 2014;48:766-71.

117. Tsioutis C, Kritsotakis EI, Karageorgos SA, Stratakou S, Psarologakis C, Kokkini S, Gikas A. Clinical epidemiology, treatment and prognostic factors of extensively drug-resistant Acinetobacter baumannii ventilator-associated pneumonia in critically ill patients. Int J Antimicrob Agents. 2016;48:492-7.

118. Garnacho-Montero J, Amaya-Villar R, Gutierrez-Pizarraya A, Espejo-Gutierrez de Tena E, Artero-Gonzalez ML, Corcia-Palomo Y, Bautista-Paloma J. Clinical efficacy and safety of the combination of colistin plus vancomycin for the treatment of severe infections caused by carbapenem-resistant Acinetobacter baumannii. Chemotherapy. 2013;59:225-31.

119. Petrosillo N, Giannella M, Antonelli M, Antonini M, Barsic B, Belancic L, Inkaya AC, De Pascale G, Grilli E, Tumbarello M, Akova M. Clinical experience of colistin-glycopeptide combination in critically ill patients infected with Gram-negative bacteria. Antimicrob Agents Chemother. 2014;58:851-8.

120. Lenhard JR, Nation RL, Tsuji BT. Synergistic combinations of polymyxins. Int J Antimicrob Agents. 2016;48:607-13.

121. Bremmer DN, Bauer KA, Pouch SM, Thomas K, Smith D, Goff DA, Pancholi P, Balada-Llasat JM. Correlation of checkerboard synergy testing with time-kill analysis and clinical outcomes of extensively drug-resistant Acinetobacter baumannii respiratory infections. Antimicrob Agents Chemother. 2016;60:6892-5.

122. Parchem NL, Bauer KA, Cook CH, Mangino JE, Jones CD, Porter K, Murphy CV. Colistin combination therapy improves microbiologic cure in critically ill patients with multi-drug resistant gram-negative pneumonia. Eur J Clin Microbiol Infect Dis. 2016;35:1433-9. 
123. Rigatto $\mathrm{MH}$, Vieira FJ, Antochevis LC, Behle TF, Lopes NT, Zavascki AP. Polymyxin B in combination with antimicrobials lacking in vitro activity versus polymyxin $b$ in monotherapy in critically ill patients with Acinetobacter baumannii or Pseudomonas aeruginosa Infections. Antimicrob Agents Chemother. 2015;59:6575-80.

124. Corbella X, Montero A, Pujol M, Dominguez MA, Ayats J, Argerich MJ, Garrigosa F, Ariza J, Gudiol F. Emergence and rapid spread of carbapenem resistance during a large and sustained hospital outbreak of multiresistant Acinetobacter baumannii. J Clin Microbiol. 2000;38:4086-95.

125. Valencia R, Arroyo LA, Conde M, Aldana JM, Torres MJ, Fernandez-Cuenca F, Garnacho-Montero J, Cisneros JM, Ortiz C, Pachon J, Aznar J. Nosocomial outbreak of infection with pan-drug-resistant Acinetobacter baumannii in a tertiary care university hospital. Infect Control Hosp Epidemiol. 2009;30:257-63.

126. Villegas MV, Hartstein AI. Acinetobacter outbreaks, 1977-2000. Infect Control Hosp Epidemiol. 2003;24:284-95.

127. Gavalda L, Soriano AM, Camara J, Gasull R, Arch O, Ferrer M, Shaw E, Granada RM, Dominguez MA, Pujol M. Control of endemic extensively drug-resistant Acinetobacter baumannii with a cohorting policy and cleaning procedures based on the 1 room, 1 wipe approach. Am J Infect Control. 2016;44:520-4.

128. Garnacho-Montero J, Dimopoulos G, Poulakou G, Akova M, Cisneros JM, De Waele J, Petrosillo N, Seifert H, Timsit JF, Vila J, Zahar JR, Bassetti M, European Society of Intensive Care M. Task force on management and prevention of Acinetobacter baumannii infections in the ICU. Intensive Care Med. 2015;41:2057-75.

129. Wisplinghoff $H$, Paulus T, Lugenheim M, Stefanik D, Higgins PG, Edmond MB, Wenzel RP, Seifert H. Nosocomial bloodstream infections due to Acinetobacter baumannii, Acinetobacter pittii and Acinetobacter nosocomialis in the United States. J Infect. 2012;64:282-90.

130. Lee HS, Loh YX, Lee JJ, Liu CS, Chu C. Antimicrobial consumption and resistance in five Gram-negative bacterial species in a hospital from 2003 to 2011. J Microbiol Immunol Infect. 2015;48:647-54.

131. Ogutlu A, Guclu E, Karabay O, Utku AC, Tuna N, Yahyaoglu M. Effects of Carbapenem consumption on the prevalence of Acinetobacter infection in intensive care unit patients. Ann Clin Microbiol Antimicrob. 2014;13:7.

132. Wenzler E, Goff DA, Mangino JE, Reed EE, Wehr A, Bauer KA. Impact of rapid identification of
Acinetobacter Baumannii via matrix-assisted laser desorption ionization time-of-flight mass spectrometry combined with antimicrobial stewardship in patients with pneumonia and/or bacteremia. Diagn Microbiol Infect Dis. 2016;84:63-8.

133. Goff DA, Bauer KA, Mangino JE. Bad bugs need old drugs: a stewardship program's evaluation of minocycline for multidrug-resistant Acinetobacter baumannii infections. Clin Infect Dis. 2014;59(Suppl 6):S381-7.

134. Mushtaq S, Warner M, Livermore D. Activity of the siderophore monobactam BAL30072 against multiresistant non-fermenters. J Antimicrob Chemother. 2010;65:266-70.

135. Higgins PG, Stefanik D, Page MG, Hackel M, Seifert $H$. In vitro activity of the siderophore monosulfactam BAL30072 against meropenem-non-susceptible Acinetobacter baumannii. J Antimicrob Chemother. 2012;67:1167-9.

136. Page MG, Dantier C, Desarbre E. In vitro properties of BAL30072, a novel siderophore sulfactam with activity against multiresistant gram-negative bacilli. Antimicrob Agents Chemother. 2010;54:2291-302.

137. Russo TA, Page MG, Beanan JM, Olson R, Hujer AM, Hujer KM, Jacobs M, Bajaksouzian S, Endimiani A, Bonomo RA. In vivo and in vitro activity of the siderophore monosulfactam BAL30072 against Acinetobacter baumannii. J Antimicrob Chemother. 2011;66:867-73.

138. Hofer B, Dantier C, Gebhardt K, Desarbre E, Schmitt-Hoffmann A, Page MG. Combined effects of the siderophore monosulfactam BAL30072 and carbapenems on multidrug-resistant Gram-negative bacilli. J Antimicrob Chemother. 2013;68:1120-9.

139. Mushtaq S, Woodford N, Hope R, Adkin R, Livermore DM. Activity of BAL30072 alone or combined with beta-lactamase inhibitors or with meropenem against carbapenem-resistant Enterobacteriaceae and non-fermenters. J Antimicrob Chemother. 2013;68:1601-8.

140. Landman D, Singh M, El-Imad B, Miller E, Win T, Quale J. In vitro activity of the siderophore monosulfactam BAL30072 against contemporary Gram-negative pathogens from New York City, including multidrug-resistant isolates. Int J Antimicrob Agents. 2014;43:527-32.

141. Ito A, Kohira N, Bouchillon SK, West J, Rittenhouse S, Sader HS, Rhomberg PR, Jones RN, Yoshizawa H, Nakamura R, Tsuji M, Yamano Y. In vitro antimicrobial activity of S-649266, a catechol-substituted siderophore cephalosporin, when tested against non-fermenting Gram-negative bacteria. J Antimicrob Chemother. 2016;71:670-7. 
142. Landman D, Kelly P, Backer M, Babu E, Shah N, Bratu S, Quale J. Antimicrobial activity of a novel aminoglycoside, ACHN-490, against Acinetobacter baumannii and Pseudomonas aeruginosa from New York City. J Antimicrob Chemother. 2011;66:332-4.

143. Garcia-Salguero C, Rodriguez-Avial I, Picazo JJ, Culebras E. Can plazomicin alone or in combination be a therapeutic option against carbapenem-resistant Acinetobacter baumannii? Antimicrob Agents Chemother. 2015;59:5959-66.
144. Villano S, Steenbergen J, Loh E. Omadacycline: development of a novel aminomethylcycline antibiotic for treating drug-resistant bacterial infections. Future Microbiol. 2016;11:1421-34.

145. Zhanel GG, Cheung D, Adam H, Zelenitsky S, Golden A, Schweizer F, Gorityala B, Lagace-Wiens PR, Walkty A, Gin AS, Hoban DJ, Karlowsky JA. Review of eravacycline, a novel fluorocycline antibacterial agent. Drugs. 2016;76:567-88. 